\title{
HUMAN SEXUAL DIMORPHISM IN SIZE MAY BE TRIGGERED BY ENVIRONMENTAL CUES
}

\author{
SATOSHI KANAZAWA* AND DEANNA L. NOVAK $\dagger$ \\ *Interdisciplinary Institute of Management, \\ London School of Economics and Political Science, UK and \\ $\dagger$ Department of Psychology, University of California - Santa Cruz, USA
}

\begin{abstract}
Summary. Evolutionary biologists mostly assume that polygyny increases sexual dimorphism in size because, under polygyny, larger males monopolize mating opportunities and pass on their 'large male' genes to their sons. Available data on parent-child correlations in height among humans (Homo sapiens) do not support the crucial assumption that height is transmitted along sex lines. This paper instead suggests that human sexual dimorphism in size emerged, not because men got taller, but because women got shorter by undergoing early menarche in response to polygyny. It further speculates that, rather than genetically transmitted, the sexual dimorphism may emerge anew in each generation in response to the degree of polygyny in society. The analysis of comparative data supports the prediction that polygyny reduces women's height, but has no effect on men's, and is consistent with the speculation that the origin of human sexual dimorphism in size may be cultural, not genetic.
\end{abstract}

The purpose of this brief research note is first to call attention to a theoretical puzzle in the area of human sexual dimorphism in size and present logical problems in the currently accepted solution. It then offers one potential solution to this puzzle, and presents some supportive data. Its purpose is not, nor does it claim, to present a comprehensive review of the literature on human sexual dimorphism in size or to provide impartial evaluation of competing hypotheses.

Since Alexander et al. (1979) and Leutenegger \& Kelly (1977), evolutionary biologists have largely agreed that sexual dimorphism in size correlates positively with the degree of polygyny, both within and across species (Clutton-Brock \& Harvey, 1977; Jarman, 1983; Leutenegger, 1982). Although Gaulin \& Boster (1992) and Holden \& Mace (1999) find little evidence of correlation between polygyny and sexual dimorphism in size, their null findings are probably statistical artifacts. Gaulin \& Boster (1992) actually find an association between polygyny and sexual dimorphism in size across human societies, until they arbitrarily exclude some small samples from 
their data. Holden \& Mace (1999) first exclude populations from industrialized countries (Europe and Japan) and then use the average sexual dimorphism in their sample (1.09), rather than monomorphism (1.00), as the benchmark against which to measure the extent of sexual dimorphism in each population. Partly due to these statistical irregularities, Holden \& Mace (1999, p. 42) themselves admit that 'There was no support for the hypothesis that variation in sexual dimorphism in stature is associated with polygyny. But there are several reasons to suspect that this might be a Type II error (failure to detect a real effect).' This is especially unfortunate because they adopt the phylogenetic comparative analysis (Felsenstein, 1985) in order to minimize the likelihood of Type II error (Holden \& Mace, 1999, p. 28). Given their inconclusive results, the value of Holden \& Mace's (1999) 'phylogenetic cross-cultural analysis', at least for the study of human sexual dimorphism in size, is still moot.

The researchers in this field agree that it is polygyny that causes sexual dimorphism in size, not the other way around. While the theory of how polygyny leads to sexual dimorphism in size has never been clearly articulated (Willner \& Martin, 1985), the causal logic usually goes as follows:

(1) Relative to monogamy, polygyny creates greater fitness variance among males than among females, by allowing a few males to monopolize all females in the breeding group. Under polygyny, a few males attain great reproductive success while many remain childless, whereas almost all females reproduce more or less equally.

(2) The greater fitness variance among males increases intrasexual selective pressure among them. Under the severe physical competition for mates, only big and tall males can emerge victorious and get mating opportunities, while small and short males are left out of the reproductive opportunities altogether. At the same time, among pair-bonding species such as humans, females prefer to mate with big and tall males who can provide better physical protection for themselves and their children against predators and other males.

(3) Thus, through both intrasexual and intersexual selection, only big and tall males can reproduce and pass on their 'big and tall male' genes to their sons, while most or all females (of all sizes) reproduce and pass on their full range of sizes to their daughters. Over many generations, males will get bigger and taller, while females will retain the same distributions of height and weight in each generation.

This logic, however, crucially assumes that body size is inherited entirely or chiefly along sex lines: sons inherit their body size mostly from their fathers, and daughters inherit theirs mostly from their mothers. In order for the above mechanism to produce sexual dimorphism in size over time, big and tall males mated to an average-sized female must produce big and tall sons but average-sized daughters.

The data for humans (Homo sapiens) presented in Table 1 call this crucial assumption into question. The data come from the Finnish Twin Cohort Study, which includes all Finnish twin pairs born during the years 1938-1949 and 1975-1979 (see Silventoinen et al. (2001) for detailed descriptions of the data.) The data show that the correlation in height between father and son $(r=0 \cdot 4704 ; n=1291)$ is statistically no different from the same correlation between father and daughter $(r=0.4723 ; n=1435)$, 
Table 1. Correlations between parent's and child's height

\begin{tabular}{lll}
\hline & $r$ & $n$ \\
\hline Father-son & $0 \cdot 4704^{*}$ & 1291 \\
Father-daughter & $0 \cdot 4723^{\dagger}$ & 1435 \\
Mother-son & $0 \cdot 5019$ & 1414 \\
Mother-daughter & $0 \cdot 5271^{* \dagger}$ & 1579 \\
\hline
\end{tabular}

Note: correlations with the same superscripts are significantly different from each other at $0 \cdot 05$ (two-tailed).

Source: J. Kaprio \& K. Silventoinen (personal communication).

and the correlation in height between mother and son $(r=0 \cdot 5019 ; n=1414)$ is statistically no different from the same correlation between mother and daughter $(r=0.5271 ; n=1579)$. If these correlations are generalizable beyond this population (not sample) of Finnish twins to all parent-child pairs in all human societies during the evolutionary history, then, starting from monomorphism, sexual dimorphism cannot emerge through the mechanism outlined above, because a tall father would have equally tall sons and daughters, and a short mother would have equally short sons and daughters.

It should be emphasized that the contention is not, and the data presented in Table 1 do not demonstrate, that height is not heritable. There is in fact an incontrovertible amount of evidence to demonstrate clearly that height is highly heritable, both among humans and other species. The contention instead, and what the data in Table 1 demonstrate, is that height is not inherited entirely or chiefly along sex lines (from fathers to sons, and from mothers to daughters). There is no a priori logical reason to believe that height should be transmitted along sex lines; in fact, most highly heritable traits (such as intelligence, eye colour and hair colour) are transmitted from parents to offspring of both sexes equally. But if height is equally heritable from parents of both sexes to children of both sexes, then sexual dimorphism in size cannot emerge from monomorphism through the mechanism outline above. How, then, can human sexual dimorphism in size emerge?

At the same time, studies demonstrate that taller men (Pawlowski et al., 2000; Mueller \& Mazur, 2001; Nettle, 2002a) and shorter women (Nettle, 2002b) have greater reproductive success. Thus there is evidence for selective pressure for sexual dimorphism among humans. However, the exact mechanism for human sexual dimorphism in size has never been clearly explicated and empirically tested. This research note suggests one possible mechanism for it, and presents some supportive data.

The authors concur with Harvey \& Bennett (1985) and Pickford (1986) that human sexual dimorphism in size may have emerged, not because men have got larger, but because women have got smaller. Unlike them, however, the authors do not believe that human sexual dimorphism in size can be genetically transmitted from parents to children. Such genetic origin of human sexual dimorphism through the mother is impossible if, once again, Silventoinen et al.'s (2001) data are generalizable 
to all human populations, because then small mothers would produce equally short sons and daughters.

The authors instead suggest that sexual dimorphism in size originally emerged and is reproduced anew in each generation as a result of women's conditional (facultative) response to the prevalent institution of marriage in their society (monogamy vs polygyny). Kanazawa (2001) notes that the degree of polygyny in society has a negative effect on the mean age of menarche, such that girls growing up in polygynous societies undergo puberty earlier on average than their counterparts growing up in monogamous societies. He argues that this might be because, by allowing some men to monopolize all reproductive women, polygyny creates an artificial shortage of such women, and selects for girls experiencing early menarche and becoming fertile. Early maturing girls have a distinct reproductive advantage under polygyny, but not under monogamy, where most mature men are already married and cannot marry again.

If polygyny decreases the mean age of menarche, and if girls experiencing earlier menarche stop growing at a younger age and thus end up with a shorter adult height than girls undergoing later menarche, then polygyny can increase sexual dimorphism in size by making women shorter while keeping men's height the same. And such sexual dimorphism in size can emerge anew in each generation in response to the prevalent degree of polygyny in society. Under some usually unrealized ideal conditions of complete monogamy, where men and women have the same fitness variance, women on average might become as tall as men; there may be nothing that is preventing women genetically from growing as tall as men. The fact that human sexual dimorphism in size is not apparent at birth and does not appear until after puberty (Willner \& Martin, 1985, pp. 4-7) is consistent with this speculation. However, women on average always end up shorter than men because every human society is polygynous to some degree, including conditions of serial polygyny in nominally monogamous societies. Five-sixths of all human societies are polygynous (Murdock, 1981), and divorce and remarriage, at least under some circumstances, are allowed in all known human cultures (Betzig, 1989; Fisher, 1989). (Serial polygyny in monogamous societies also creates an artificial shortage of reproductive women because many divorced, and therefore available, women are past their reproductive prime.) As a result, fitness variance among men is always greater than that among women in every human society (Daly \& Wilson, 1988, pp. 140-142; Trivers, 1972) and there is always an artificial shortage of reproductive women, selecting for earlier menarche and shorter stature among girls.

If this conditional theory of human sexual dimorphism in size is correct, then it leads to two immediate empirical hypotheses. First, at the micro (individual) level, girls who experience early menarche should have shorter adult height than those who experience late menarche; in fact, this assumption is crucial for the theory's logic. A large number of studies throughout the world demonstrate that this is indeed the case (Frisch \& Revelle, 1970; Helm et al., 1995; Jaruratanasirikul et al., 1997; Biro et al., 2001; Okasha et al., 2001; Nettle 2002b). These studies collectively show that girls who experience early menarche on average attain shorter adult height than those who experience late menarche. There is thus empirical support for the crucial micro-level assumption of the theory. 
Second, at the macro (societal) level, the degree of polygyny in society should have a negative effect on women's mean height (making them shorter) but no effect on men's mean height. Women in polygynous societies should be shorter than women in monogamous societies, while men's height should not vary as a function of the marriage institution. The authors have compiled a large comparative data set in order to test this second hypothesis of the theory. The dependent variable, men's and women's mean height in society, is taken from Eveleth \& Tanner (1976) and Eveleth \& Tanner (1990). While these are the first and the second editions of the same book, studies compiled in the two editions have almost no overlaps between the two. All non-overlapping studies from the two editions are included in the data.

There are three alternative measures of polygyny to predict men's and women's mean height. 'Effective polygyny $15-19$ ' is the difference between the proportion of women aged 15-19 who are currently married and the same proportion of men in the same age group. 'Effective polygyny 20-24' is the same difference for the 20-24 age group. In highly polygynous societies, older and wealthier (and therefore more desirable) men monopolize all young and desirable women, while young men are often left mateless. So the sex difference in the proportion married in the young age groups is a good measure of effective polygyny in the society. Further, for the same reason, women tend to marry at a younger age in polygynous societies than in monogamous societies (Kanazawa, 2001). The mean age difference between the groom and the bride is 3.0 in largely monogamous societies, and 4.5 in largely polygynous societies $(t=4 \cdot 18, p<0 \cdot 001)$. Women's mean age of marriage is therefore an oblique measure of polygyny.

In addition to the main predictor of men's and women's height (polygyny), there are three control variables in the multiple regression equations. First, since the mean height of a population can be strongly affected by the nutritional conditions in the society, the equations contain GDP per capita as a measure of economic development and welfare. GDP per capita correlates very strongly with life expectancy at birth $(r=0.6377, p<0.0001, n=574$, with female life expectancy, and $r=0.6268, p<0.0001$, $n=574$, with male life expectancy), so it is safe to assume that GDP is a very good measure of health care, diet, nutrition and other factors that may affect stature. Since people of different races are known to have different average heights, the equations also contain two dummies to control for the race of the sample (with the white sample as the reference category). All the variables are available either in Eveleth \& Tanner (1976, 1990) or other published sources (United Nations, 1992, 2000).

Table 2 presents the results of the multiple regression analyses. As predicted, measures of polygyny have a strong negative effect on women's height. Controlling for GDP per capita and the race of the samples, each percentage point of sex difference in the proportion married in the 15-19 age group decreases women's mean height by $0 \cdot 10$ centimetres $(p<0 \cdot 01)$. The same percentage point among the $20-24$ age group decreases women's mean height by 0.12 centimetres $(p<0.001)$. One year decrement in the mean age of marriage among women decreases women's mean height by 0.70 centimetres $(p<0.05)$. In stark contrast, none of these measures of polygyny has a statistically significant effect on men's mean height across societies.

The available data support both the micro-level prediction (girls who experience early menarche attain shorter adult height than those who experience late menarche) 


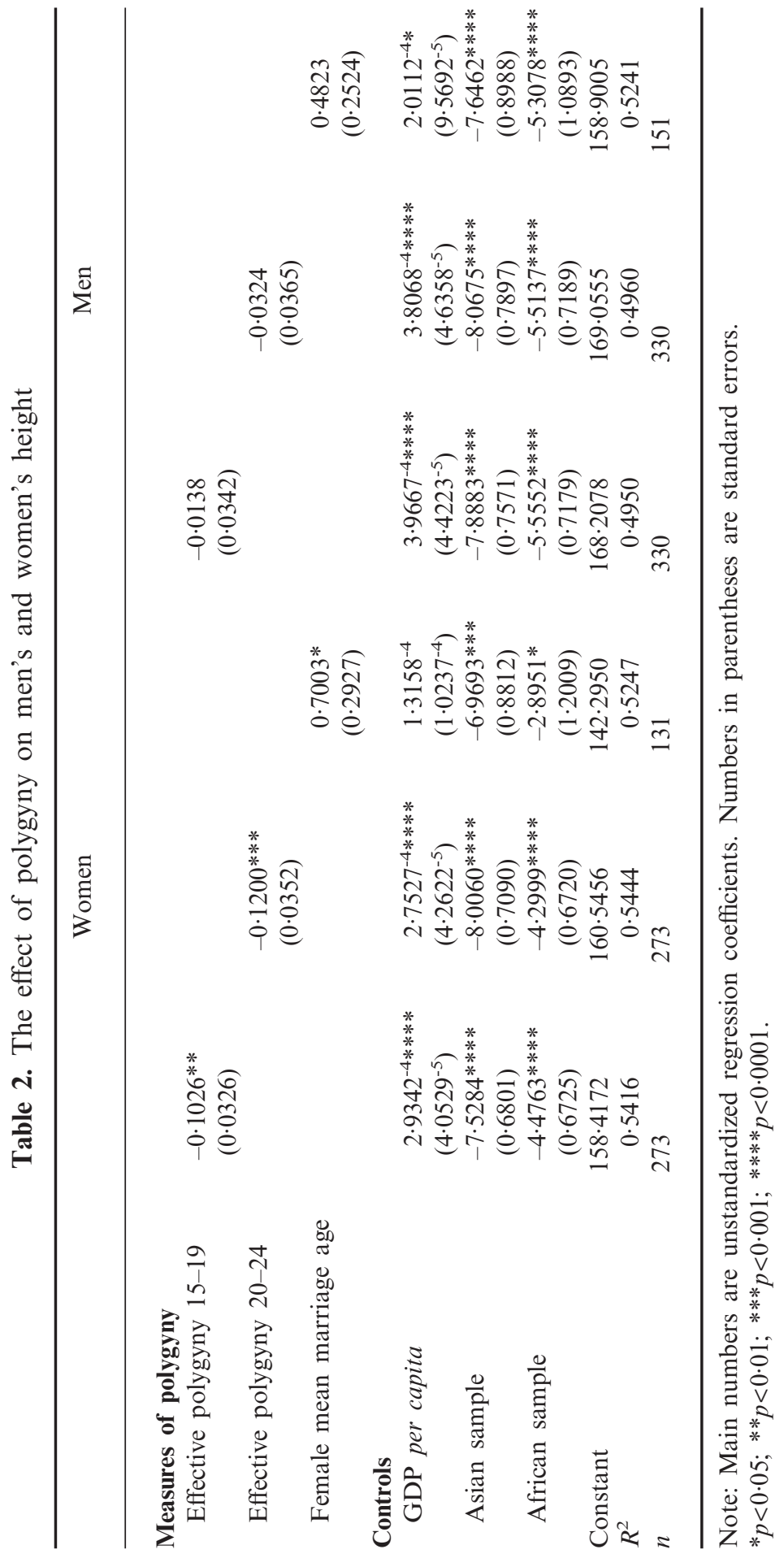


and the macro-level prediction (the degree of polygyny has a negative effect on women's height across societies, but not on men's). It therefore appears that polygyny leads to sexual dimorphism in size among human populations, not by making men bigger and taller, as has hitherto been almost universally assumed (with the exceptions of Willner \& Martin (1985) and Pickford (1986)), but by making women smaller and shorter.

The precise mechanism by which polygyny depresses the adult female height by precipitating early menarche is still unknown. Ellis et al. (1999) show that the quality of paternal investment into girls (measured, inter alia, by the time spent by the father in childcare and the affection shown by him toward his daughter) delays girls' puberty. Since polygyny by definition decreases the amount of time the father can spend with his children by each wife (Kanazawa, 2001), Ellis et al.'s (1999) findings are consistent with this paper's theoretical contention. Ellis (2002) further speculates that pheromones from the biological father might be the biochemical agent that actually delays the girl's onset of puberty.

The alternative theory presented in this research note suggests that human sexual dimorphism in size may not be genetic in origin or transmission, but rather appears anew in each generation as a result of women's conditional response to the degree of polygyny in their society. This note only presents preliminary results in support of the speculation. Future research must determine whether the findings are robust and whether the authors' speculation is correct.

\section{Acknowledgments}

The authors thank Jaakko Kaprio and Karri Silventoinen for sharing their unpublished data from the Finnish Twin Cohort Study, and Bruce J. Ellis, Daniel Nettle and Karri Silventoinen for the comments on earlier drafts.

\section{References}

Alexander, R. D., Hoogland, J. L., Howard, R. D., Noonan, K. M. \& Sherman, P. W. (1979) Sexual dimorphisms and breeding systems in pinnipeds, ungulates, primates and humans. In Chagnon, N. A. \& Irons, W. (eds) Evolutionary Biology and Human Social Behavior: An Anthropological Perspective. Duxbury Press, North Scituate, pp. 402-435.

Betzig, L. (1989) Causes of conjugal dissolution: a cross-cultural study. Current Anthropology 30, 654-676.

Biro, F. M., McMahon, R. P., Striegel-Moore, R., Crawford, P. B., Obarzanek, E., Morrison, J. A., Barton, B. A. \& Falkner, F. (2001) Impact of timing of pubertal maturation on growth in black and white female adolescents: the national heart, lung, and blood institute growth and health study. Journal of Pediatrics 138, 636-643.

Clutton-Brock, T. H. \& Harvey, P. H. (1977) Primate ecology and social organization. Journal of Zoology 183, 1-39.

Daly, M. \& Wilson, M. (1988) Homicide. De Gruyter, New York.

Ellis, B. J. (2002) Of fathers and pheromones: implications of cohabitation for daughters pubertal timing. In Booth, A. \& Crouter, A. C. (eds) Just Living Together: Implications of Cohabitation on Families, Children, and Social Policy. Lawrence Erlbaum, Mahwah, pp. 161-172. 
Ellis, B. J., McFadyen-Ketchum, S., Dodge, K. A., Pettit, G. S. \& Bates, J. E. (1999) Quality of early family relationships and individual differences in the timing of pubertal maturation in girls: a longitudinal test of an evolutionary model. Journal of Personality and Social Psychology 77, 387-401.

Eveleth, P. B. \& Tanner, J. M. (1976) Worldwide Variation in Human Growth. First Edition. Cambridge University Press, Cambridge.

Eveleth, P. B. \& Tanner, J. M. (1990) Worldwide Variation in Human Growth. Second Edition. Cambridge University Press, Cambridge.

Felsenstein, J. (1985) Phylogenies and the comparative method. American Naturalist 125, 1-15.

Fisher, H. (1989) Evolution of human serial pairbonding. American Journal of Physical Anthropology 78, 331-354.

Frisch, R. E. \& Revelle, R. (1970) Height and weight at menarche and a hypothesis of critical body weights and adolescent events. Science 169, 397-398.

Gaulin, S. J. C. \& Boster, J. S. (1992) Human marriage systems and sexual dimorphism in stature. American Journal of Physical Anthropology 89, 467-475.

Harvey, P. H. \& Bennett, P. M. (1985) Sexual dimorphism and reproductive strategies. In Ghesquiere, J., Martin, R. D. \& Newcombe, F. (eds) Human Sexual Dimorphism. Taylor and Francis, London, pp. 43-59.

Helm, P., Münster, K. R. \& Schmidt, L. (1995) Recalled menarche in relation to infertility and adult weight and height. Acta Obstetricia et Gynecologica Scandinavica 74, 718-722.

Holden, C. \& Mace, R. (1999) Sexual dimorphism in stature and women's work: a phylogenetic cross-cultural analysis. American Journal of Physical Anthropology 110, 27-45.

Jarman, P. J. (1983) Mating system and sexual dimorphism in large, terrestrial, mammalian herbivores. Biological Review 58, 485-520.

Jaruratanasirikul, S., Mo-suwan, L. \& Lebel, L. (1997) Growth pattern and age at menarche of obese girls in a transitional society. Journal of Pediatric Endocrinology and Metabolism 10, 487-490.

Kanazawa, S. (2001) Why father absence might precipitate early menarche: the role of polygyny. Evolution and Human Behavior 22, 329-334.

Leutenegger, W. (1982) Sexual dimorphism in nonhuman primates. In Hall, R. L. (ed.) Sexual Dimorphism in Homo Sapiens: A Question of Size. Praeger, New York, pp. 11-36.

Leutenegger, W. \& Kelly, J. T. (1977) Relationship of sexual dimorphism in canine size and body size to social, behavioral, and ecological correlates in anthropoid primates. Primates $\mathbf{1 8}$, $117-136$.

Mueller, U. \& Mazur, A. (2001) Evidence of unconstrained directional selection for male tallness. Behavioral Ecology and Sociobiology 50, 302-311.

Murdock, G. P. (1981) Atlas of World Cultures. University of Pittsburgh Press, Pittsburgh.

Nettle, D. (2002a) Height and reproductive success in a cohort of British men. Human Nature 13, 473-491.

Nettle, D. (2002b) Women's height, reproductive success and the evolution of sexual dimorphism in modern humans. Proceedings of the Royal Society of London Series B 269, 1919-1923.

Okasha, M., McCarron, P., McEwen, J. \& Davey Smith, G. (2001) Age at menarche: secular trends and association with adult anthropometric measures. Annals of Human Biology 28, 68-78.

Pawlowski, B., Dunbar, R. I. M. \& Lipowicz, A. (2000) Tall men have more reproductive success. Nature 403, 156.

Pickford, M. (1986) On the origins of body size dimorphism in primates. In Pickford, M. \& Chiarelli, B. (eds) Sexual Dimorphism in Living and Fossil Primates. Il Sedicesimo, Florence, pp. $77-91$. 
Silventoinen, K., Kaprio, J., Lahelma, E., Viken, R. J. \& Rose, R. J. (2001) Sex differences in genetic and environmental factors contributing to body-height. Twin Research 4, 25-29.

Trivers, R. L. (1972) Parental investment and sexual selection. In Campbell, B. (ed.) Sexual Selection and the Descent of Man 1871-1971. Aldine, Chicago, pp. 136-179.

United Nations (1992) Demographic Yearbook 1990. United Nations, New York.

United Nations (2000) Statistical Yearbook 1997. United Nations, New York.

Willner, L. A. \& Martin, R. D. (1985) Some basic principles of mammalian sexual dimorphism. In Ghesquiere, J., Martin, R. D. \& Newcombe, F. (eds) Human Sexual Dimorphism. Taylor \& Francis, London, pp. 1-42. 